02 Royal Netherlands Institute for Sea Research

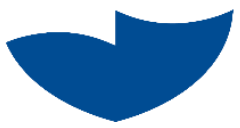

This is a postprint of:

Sassi, M.G., Gerkema, T., Duran-Matute, M. \& Nauw, J.J. (2016). Residual water transport in the Marsdiep tidal inlet inferred from observations and a numerical model. Journal of Marine Research, 74(1), 21-42

Published version: $\underline{\mathrm{dx} . \text { doi.org/10.1357/002224016818377586 }}$

Link NIOZ Repository: $\underline{w w w . v l i z . b e / n l / i m i s ? m o d u l e=r e f \& r e f i d=260125}$

[Article begins on next page]

The NIOZ Repository gives free access to the digital collection of the work of the Royal Netherlands Institute for Sea Research. This archive is managed according to the principles of the Open Access Movement, and the Open Archive Initiative. Each publication should be cited to its original source - please use the reference as presented.

When using parts of, or whole publications in your own work, permission from the author(s) or copyright holder(s) is always needed. 


\title{
1 Residual water transport in the Marsdiep tidal inlet 2 inferred from observations and a numerical model
}

\author{
$3 \quad$ M.G. (Maximiliano) Sassi ${ }^{1}$, T. (Theo) Gerkema ${ }^{1}$, M. (Matias) \\ 4 \\ Duran-Matute ${ }^{1,2}$, and J.J. (Janine) Nauw ${ }^{1}$ \\ $5 \quad{ }^{1}$ Department of Physical Oceanography, NIOZ Royal Netherlands Institute for Sea Research, \\ 6 \\ Landsdiep 4, 1797 SZ, 't Horntje (Texel), The Netherlands \\ $7 \quad{ }^{2}$ Department of Applied Physics, Turbulence and Vortex Dynamics, TUE Eindhoven University \\ 8 \\ of Technology, Eindhoven, The Netherlands


11 At tidal inlets large amounts of water are exchanged with the adjacent sea during the tidal 12 cycle. The residual flows, the net effect of ebb and flood, are generally small compared 13 to the gross flux, they vary in magnitude and sign from one tidal period to the other, and 14 their long-term mean varies from year to year. Here we focus on the temporal variability 15 of the residual flows in the Marsdiep tidal inlet, which is the western-most inlet of the 16 Wadden Sea, a tidal lagoon along the coasts of the Netherlands, Germany and Denmark.

17 We compare the transport from a high-resolution numerical model with the transport from velocity profile data collected beneath a ferry that crosses the inlet daily. The comparison works in two ways: for the areas and times covered by the measurements, the data serves

20 to validate the model, and conversely, the model is employed to assess the consequences 21 of spatial and temporal gaps in the data. Modeled and observed transports over the region 22 of the flow that is covered by the ADCP are in good agreement for gross and residual quantities. Results indicate that uncertainties due to spatial gaps can be overcome with a simple extrapolation approach applied to the velocity profiles, whereas uncertainties due 25 to temporal gaps are more problematic and leave large discrepancies in the residuals. 


\section{List of Figures}

271 Top panel: bathymetry of the Dutch Wadden Sea (DWS) and domain of the numerical model. The red square encloses the study site shown in the lower panel. Bottom panel: location of deployment of the moored frame (red plus symbol) and track of the ferry for the year of 2009 (black solid lines). Water depth is in meters with respect to the national vertical datum.

2 East component of the depth-mean current vector from model and observations. Positive values indicate flood. The time difference in zerocrossing of observed and modeled series is generally greater for Slack Before Ebb (SBE) than for Slack Before Flood (SBF). . . . . . . . . . . . 13

3 Black lines show the profiles of the East velocity component normalized with the corresponding depth-mean velocity, for model and observations during ebb and flood phases. Profiles shown correspond with those for which the magnitude of the depth-mean velocity is greater than $0.1 \mathrm{~m} \mathrm{~s}^{-1}$. The red lines show the median. . . . . . . . . . . . . . . . . . 14

4 Harmonic analysis (using t_tide) performed on current-vector velocity profiles from observations (black) and simulations (red). The main five tidal constituents are shown, as described (left panels: major semi-axis; right panels: orientation). Thin lines indicate the error bands. . . . . . . . . . 16

5 Track of the ferry overlaying the model grid. The red dots indicate the grid points employed for comparison and can be grouped into consecutive transects approximately spanning the inlet from West to East. . . . . . . . 17 
6 Properties of scatter plots between observed and modeled (as explanatory variable) velocities. For each grid point, a linear regression between time-series of the East component of observed and modeled velocities for flood periods yields the slope, the offset and the RMSE of the residuals. Model grid points were grouped into transects across the Marsdiep (left and right sides of the transect approximately correspond with South and North coastlines of the inlet). Panels from top to bottom represent transects approximately distributed from West to East (see Fig. 5). Also shown the location of the water surface and the bottom. . . . . . . .

7 Comparison between the modeled and the observed transport obtained by combining data from the two ADCPs. Modeled transport has been exclusively obtained for areas overlapping with the measured profiles. The panel to the right shows a scatter plot between observations and simulations at times corresponding with the observations. The black line is the one to one line. The red line is the best fit line with slope and offset as described. The panel below shows a sub sample of the time series for a period of about 12 days. . . . . . . . . . . . . . .

8 Residuals are computed over predefined integration periods (continuous magenta line with crosses indicating start and end of the interval). The tidal period was defined as the time difference between two consecutive up-crossings of the volume of water of the entire DWS through the median volume (see Duran-Matute et al., 2014). To compare the residuals obtained with the model and the observations, we choose those intervals that are fully covered by ADCP data. In this example we select the two

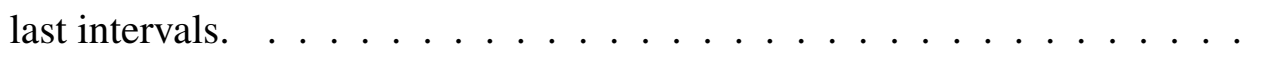


9 Left: time series of residual transport for the year 2009 from model (continuous red line), and observations (black dots) for the tidal periods that are fully covered by ADCP data. The mean bias is $800 \mathrm{~m}^{3} \mathrm{~s}^{-1}$ and the RMSE is $1200 \mathrm{~m}^{3} \mathrm{~s}^{-1}$. Right: scatter plot with observations as explanatory variably. The black line is the one to one line, and the red line indicates the best fit line with a slope of 1.08 and an offset of $300 \mathrm{~m}^{3} \mathrm{~s}^{-1} \ldots \ldots$. . .

\section{List of Tables}

1 Median, mean and Standard Deviation (SD) of the residual transport for the year 2009, and summary of statistics of the comparison between the residual transport using all measurements (first column) and corresponding estimates based on several approaches with extrapolation towards unmeasured areas (the rest of the columns). The constant extrapolation method (const) assumes that the uppermost (lowermost) velocity bin is normative of the top (bottom) layer. The linear extrapolation method (lin) assumes that the transport in the top layer is determined by the gradient of the three uppermost bins whereas the transport in the bottom layer is determined by linear interpolation between the lowermost bin and zero at the bottom. 'Bot' stands for bottom layer, 'Top' for surface layer, and 'Mid' for middle (measured) layer. All quantities are in $\mathrm{m}^{3} \mathrm{~s}^{-1}$ except for the slope that has no units. . . . . . . . . . . . . 25

2 Harmonic analysis (using t_tide) on the time series of the modeled transport for the year 2009 (Full), on the same series but restricting the times to daily ferry crossings (6AM-10PM), and further restricting the series to the actual dates and times that the ferry crossed the inlet during the year 2009 (ADCP scope). We obtain amplitudes and phases of several tidal constituents (59 in total) and show here a subset of the most important ones. 26 
3 Summary of statistics of the residuals for the year 2009 based on the full series (Full), the series restricted to the times of the ferry crossing (6AM10PM), the series with gaps as in the observations (ADCP scope), and the residuals obtained by subtracting from the full series the reconstructed series obtained with harmonic analysis. Also shown the Pearson's $r$ between estimates with the full series (first row, assumed here to be the true residual transport) and estimates with all other approaches (the rest of the rows). All quantities in $\mathrm{m}^{3} \mathrm{~s}^{-1}$, except for the skewness and the coefficient of correlation that have no units. . . . . . . . . . . . .

\section{Introduction}

In multiple-inlet systems like the Wadden Sea, large amounts of water are being exchanged with the adjacent sea during the tidal cycle. For any particular inlet, the amount entering with flood is generally unequal to the amount leaving with ebb, in other words, there is a residual transport over a tidal period. Residual flows are very difficult to assess because they are often small compared to the gross flux, they vary in magnitude and sign from one tidal period to the other, and their long-term mean varies even from year to year (Nauw et al., 2014; Duran-Matute and Gerkema, in prep). Because of this variability at short- and long-term scales, one needs long-term and continuous measurements and/or simulations to obtain an estimate of the mean, median and standard deviation of the residual flow.

At a given inlet of a multiple-inlet system, the residual flow may vary in response to the flows at all other inlets. Therefore, circulation patterns arise as a consequence of the combined effects of the tides, the freshwater discharge (and the accompanying density gradients), and the overall weather conditions, particularly, the wind. Tidal distortion and nonlinear tidal processes affect the exchange between tidal basins and ultimately the morphodynamic stability (van de Kreeke, 1990; Salles et al., 2005; Pacheco et al., 2010). 
Studies focusing on the variability of wind and its influence on the residual flows are rare. In a recent study by $\mathrm{Li}$ (2013), the net transport at subtidal frequencies was assessed with observations and an idealized numerical model. They found that wind-induced residual flows can overwhelm the residual circulation patterns induced by the tides. Wind is known to drive residual circulation in estuaries because surface shear stress forces surface currents and causes mixing. At the entrance of Chesapeake Bay subtidal exchange is dominated by local and remote winds (Valle-Levinson et al., 2001; Wong and Valle-Levinson, 1998). Down-estuary wind strains the along-channel density gradient to increase stratification whereas up-estuary wind reduces the vertical shear and stratification (Scully et al., 2005). Wind-driven mixing can be of the same order and even greater than tidal mixing, and may occur not only during extreme events (Chen and Sanford, 2009). Numerical models can be employed to consistently resolve residual circulation patterns that can be analyzed synoptically in space and in time (Esparza et al., 2014). However, numerical models require thorough validation that is typically conducted with in situ observations.

Incidental observations are not appropriate to untangle the effects of wind on the residual circulation because of the episodic nature of wind. Long-term and semi-continuous measurements of the volumetric transport can be obtained using acoustic Doppler current profilers (ADCPs) on board a ferry crossing the inlet (e.g. Codiga and Aurin, 2007). In the Wadden Sea, such observations are available on board the TESO ferry crossing the Marsdiep inlet since 1998 (Buijsman and Ridderinkhof, 2007a; Nauw et al., 2014). The ferry operates daily, typically from $6 \mathrm{AM}$ to $10 \mathrm{PM}$, and velocity profiles are obtained between $6.5 \mathrm{~m}$ below the water surface to the bottom, excluding the near-bottom part (about $6 \%$ of the local water depth) due to side-lobe interference. Since the residual flow is very small compared to the gross volumes transported during ebb and flood, a small error in the gross transport greatly diminishes the reliability of the estimates of the residual. The purpose of this paper is to assess the importance of the temporal and spatial gaps in such observations by comparing the data with results from a high-resolution numerical model, presented be- 
fore by Duran-Matute et al. (2014). This comparison works in two ways. First, for the areas and times covered by the measurements, the data serves to validate the model. Second, for the areas and times not covered by the measurements, the model can be employed to assess the consequences of these gaps, and suggest possible ways to correct for them.

The residual transport of water in the Marsdiep has been assessed with models and observations before. Tides alone can force a mean outflow through the inlet of about $800 \mathrm{~m}^{3} \mathrm{~s}^{-1}$ (Ridderinkhof, 1988a), which was explained with an analytical model by the amplitude differences between the several inlets of the Dutch Wadden Sea (DWS) (Ridderinkhof, 1988b). By expanding that model to include wind effects, Buijsman and Ridderinkhof (2007b) showed that wind can produce highly variable residual flows, and based on observations for the period 1998-2002 they estimated an average outflow rate of about $3000 \mathrm{~m}^{3} \mathrm{~s}^{-1}$ (Buijsman and Ridderinkhof, 2007a). However, more detailed estimates by Nauw et al. (2014) for the set of observations spanning the period 2003-2006 show a large inter-annual variability of the yearly-mean in magnitude and even in sign. Estimates of the residual transport were also obtained by Elias et al. (2006), although these measurements were incidental, spanning a few days during the year. Finally, recent realistic simulations including tides, winds and freshwater discharge (Duran-Matute et al., 2014) resulted on a median outflow rate through the inlet of about $700 \mathrm{~m}^{3} \mathrm{~s}^{-1}$ for the period 2009-2010, and a residual transport that may even be reversed during strong southwesterly winds. The standard deviation for the same period amounted to about $2300 \mathrm{~m}^{3} \mathrm{~s}^{-1}$, which again by far exceeds the residual itself, indicating the high degree of variability in the system.

Because both inter- and intra-annual variability are large compared with the mean, it is important to compare the measured and simulated transport for the same year. Here we carry out this comparison for the year 2009. We notice that Duran-Matute et al. (2014) already tested the same model against the same dataset; however, they have not addressed the discrepancies between model and observations. The discrepancy between model and observations will be explained here by looking critically into the model limitations, and 
the temporal and spatial limitations inherent to the ferry-based ADCP measurements. The rest of this paper is organized as follows. In Section 2. we describe the study site, the flow measurements and the numerical model. Section 3. presents the validation of the numerical model with the flow measurements. Section 4. discusses the uncertainty in residual transport estimates. In Section 5. and 6. we provide respectively with a discussion and the conclusions.

\section{Materials and Methods}

\section{a. Study Site}

The Marsdiep inlet (Figure 1) separates the island of Texel from mainland NorthHolland and is one of the major passages for the exchange of water, nutrients and sediments between the North Sea and the DWS. The inlet is about $4 \mathrm{~km}$ wide and maximum depth in our study area reaches about $28 \mathrm{~m}$. Semidiurnal tides are the major driver of water transport in the Marsdiep inlet, but there is a noticeable diurnal inequality as well. The dominant wind direction is from the southwest. Part of the freshwater outflow from the lake IJssel finds its way through the Marsdiep inlet. The mean annual freshwater discharge of all combined sources into the DWS typically amounts to about $500 \mathrm{~m}^{3} \mathrm{~s}^{-1}$.

\section{b. Flow Measurements}

i. Ferry Transects Two ADCPs (RDI $1200 \mathrm{kHz}$ Workhorse) are mounted beneath the hull of the TESO ferry that crosses the Marsdiep inlet every 30 min on a daily basis from about 6 AM to 10 PM (Figure 1). Each crossing takes about 15 min and the ADCPs are placed toward the bow and the stern of the ferry. The ferry maintains the same relative orientation on northward and southward crossings as the ferry propulsion switches direction depending on the direction of the crossing. Later on we choose to use velocity observations only from the ADCP that is forward (in the direction of travel) from the ship's propeller to avoid bubble-induced noise - this effectively means that one ADCP is used 

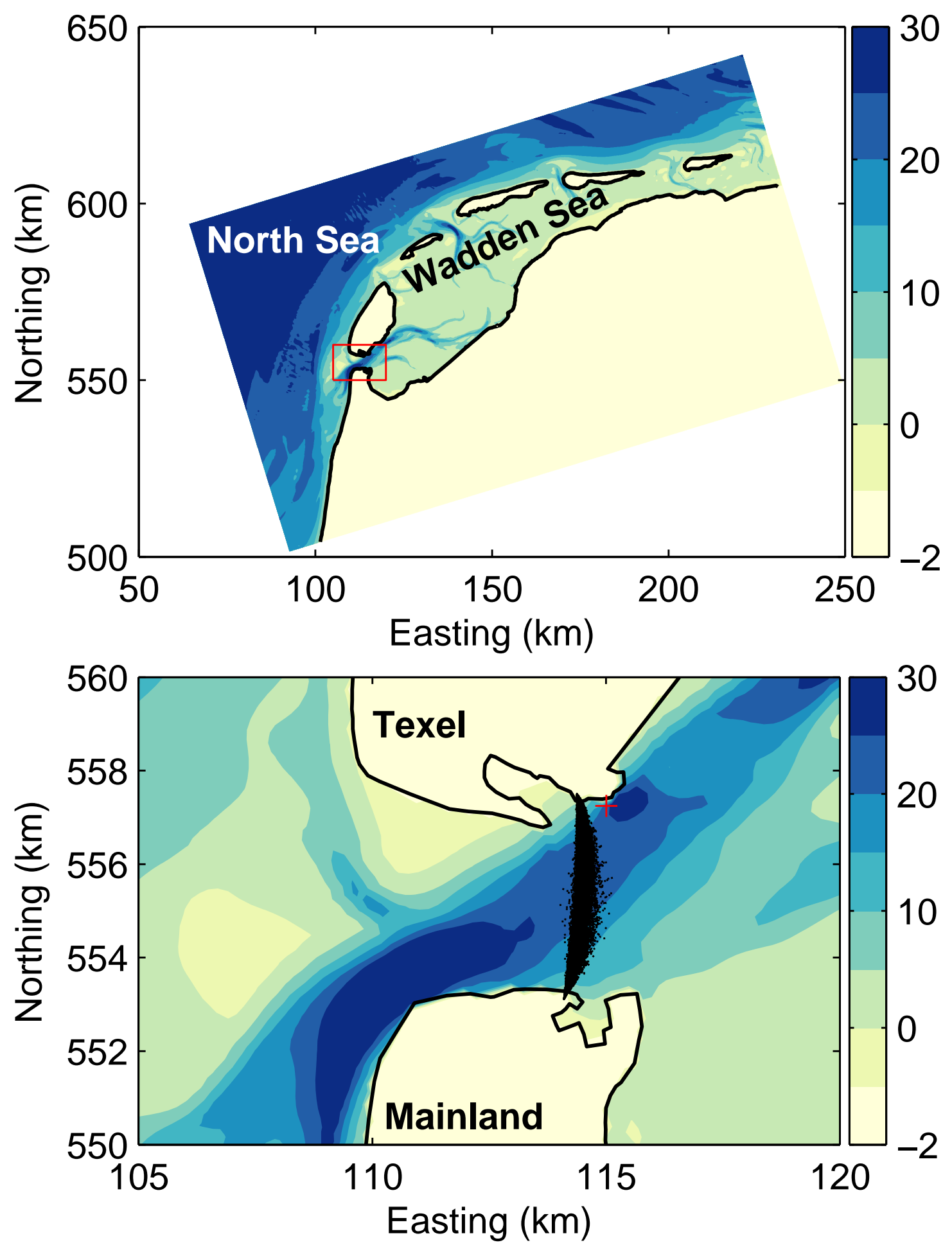

Figure 1: Top panel: bathymetry of the Dutch Wadden Sea (DWS) and domain of the numerical model. The red square encloses the study site shown in the lower panel. Bottom panel: location of deployment of the moored frame (red plus symbol) and track of the ferry for the year of 2009 (black solid lines). Water depth is in meters with respect to the national vertical datum. 
on northward transects and the other ADCP is used on southward transects. The hull of the ferry is located at about $5 \mathrm{~m}$ below the water surface so the first ADCP bin is located at 6.5 $\mathrm{m}$ depth. Profiles are acquired with a constant bin size of $0.5 \mathrm{~m}$. Maximum water depth limits the temporal sampling resolution of a profile to about $1.3 \mathrm{~s}$ and each ensemble is composed of one single ping. Velocity data is retrieved in beam coordinates and the Bottom Tracking (BT) system is available. The ferry is fitted with an external gyro-compass and a differential Global Positioning System (dGPS). Flow profiles are retrieved in beam coordinates, corrected for vessel motion and transformed to geographical coordinates. The last two procedures are further explained in the next paragraph.

Velocity profiles obtained with moving-vessel ADCPs are generally subject to uncertainty due to positioning, heading offsets, and tilt angles (e.g. Muste et al., 2004; GonzalezCastro and Muste, 2007). Most of these sources of error are here significantly reduced due to the stability of the ferry and because the ferry hardly makes a turn as it moves from one side to the other of the inlet. Magnetic disturbances induced by the ferry's hull can affect the internal compass reading (Trump and Marmorino, 1997), so we only employ the external heading in the calculations. Heading offsets are recorded on a logbook and also retrieved from the difference between the headings recorded by the internal and external compasses. Discrepancies between the ship speed computed with the BT and dGPS systems are small when averaged over a transect and show spatial variations that might be associated with bed-load sediment transport (e.g. Sassi et al., 2011b). Spatial patterns of bed-load transport in the Marsdiep inlet display inward (outward) direction in the southern (northern) part of the inlet (Buijsman and Ridderinkhof, 2008b), therefore, bias due to bed-load transport may cancel out throughout the transect. Here we choose to use the BT system to correct for vessel motion to avoid heading biases introduced by the dGPS, and because bed-load transport cannot induce an appreciable bias in the measured profiles.

The volumetric transport over a given transect is obtained as follows: for each measured velocity profile we compute the cross-product between the horizontal components 
231 of the flow speed and ship speed vectors, and integrate this quantity over the vertical and

over the time interval that takes the ferry to sail from one side of the inlet to the other (see Sassi et al., 2011a). We assume this estimate to be instantaneous. The actual transport across the section is given by this measured transport plus any transport through parts of the transect that are not covered by the instrument. The ferry enters a sheltered dock on both sides of the inlet, so the only two areas not covered by the ADCP are a near-bed region missed due to side-lobe interference of the ADCP beams, amounting to $6 \%$ of the distance between the transducer and the bottom, and a constant thickness layer of 6.5 $\mathrm{m}$ near the surface. Since wind and salinity gradients induce departures of the velocity profiles in the near-surface region, extrapolating velocity profiles toward the surface is likely to introduce large errors in the computed transport. It is worthwhile noting that the present approach for estimating the volumetric transport is more reliable and features less assumptions (e.g. vector decomposition) than in previous studies (Codiga and Aurin, 2007; Buijsman and Ridderinkhof, 2007a).

ii. Moored Frame An instrumented frame equipped with one upward-looking ADCP (RDI $1200 \mathrm{kHz}$ Workhorse) was deployed in April and May 2009 for approximately 16 days at a location with water depth of about $25 \mathrm{~m}$ (Figure 1). The first ADCP bin was located at $1.5 \mathrm{~m}$ above the bed and bin size was $1 \mathrm{~m}$. Every 5 minutes, an ensemble average containing 60 profiles was constructed and stored. Velocity profiles were recorded in geographical coordinates using the internal heading of the instrument. Tilt angles ranged in between $-6^{\circ}$ to $2^{\circ}$ for the roll, and $-14^{\circ}$ to $-6^{\circ}$ for the pitch. Surface reflections due to side-lobe effects (again $6 \%$ of the distance between the transducer and the bottom) were removed in processing the data. The resulting profiles extend approximately from near the bottom to near the surface, allowing to resolve the flow over the entire water column. 


\section{c. Numerical Model}

The model employed in this study has been extensively described by Duran-Matute et al. (2014) and here we limit the discussion to the most important features. The numerical model GETM (e.g. Stanev et al., 2003) is a finite difference model that solves the three-dimensional hydrostatic equations of motion with the Boussinesq approximation and the eddy viscosity assumption. The model solves the equations for potential temperature (in degrees Celsius) and salinity (in the practical salinity scale), and includes a wetting and drying algorithm. Model setup consists of a grid with spatial resolution of $200 \mathrm{~m}$ (Figure 1) and 30 sigma-layers in the vertical. At open boundaries in the North Sea, surface elevation (tides and wind set-up), depth-mean current, and vertical profiles of salinity and temperature are imposed. The model is forced at the boundaries with results from an operational larger scale numerical model with data assimilation. In this way, the model has no individual constituents but the forcing implicitly involves all the relevant tidal constituents. A rigid wall is placed on the watershed at the Eastern boundary, leaving the Ems estuary out of the model domain. Meteorological forcing includes wind speed and direction, air temperature, precipitation, cloudiness and dew point. Freshwater discharge from 12 different sluices into the domain are included with a temporal resolution of 10 min, as described by Duran-Matute et al. (2014).

Eddy viscosity and eddy diffusivity are parameterized using the General Ocean Turbulence Model (GOTM) and the turbulence closure employed is the $\kappa$ - $\epsilon$ model (e.g. Burchard and Baumert, 1995). The velocity at the bottom layer is parameterized with a logarithmic profile and using a constant roughness length of $1.7 \mathrm{~mm}$. High-resolution depth-soundings spanning the years 1996 to 2012 were employed to construct the bathymetry of the domain. To avoid numerical noise and model instability, the bathymetry map was further smoothed. The time step for the three-dimensional fields is $40 \mathrm{~s}$ long, and the variables of interest are outputted every half an hour. Simulations start from rest in November 2008 and a spin-up of two months is adopted. The full year of 2009 is then simulated. The model results 
compare very well with observations such as those from tidal-gauge stations, time-series of salinity and temperature, and gross water transports estimated using ferry-based ADCP measurements (see Duran-Matute et al. (2014) for details). The last comparison will be further explored here.

\section{Validation Numerical Model}

In what follows, we compare in detail velocity profiles from the model and the observations for two different datasets. First, at a fixed location, velocity profiles from the moored frame spanning nearly the full water column and measured for 16 days are compared to model output. Second, across the inlet, measured profiles from the TESO-ferry spanning the entire year of 2009 are compared with the model output at locations corresponding with the model's grid. Finally, we compare the gross and residual transports obtained from the model and the observations.

\section{a. Velocity Profiles at a Fixed Station}

Modeled profiles were obtained at a grid point close to the location of the moored measurements (Figure 1), and linearly interpolated to match the vertical positions of the ADCP bins. Measured velocity profiles were averaged every $30 \mathrm{~min}$ to match the temporal resolution of the model. Figure 2 shows part of the time series of the East component of the depth-mean current vector obtained from model and observations. The mean bias and Root-Mean-Squared-Error (RMSE) of the differences gives $-0.09 \mathrm{~m} \mathrm{~s}^{-1}$ and $0.14 \mathrm{~m} \mathrm{~s}^{-1}$, respectively. The time difference in zero-crossing of ADCP and model yields a mean and standard deviation of -2 and 6 min for Slack Before Flood (SBF), and -21 and 11 min for Slack Before Ebb (SBE), respectively. The time difference for SBE is generally larger than for SBF; this simply reflects the fact that the time from maximum flood to maximum ebb is longer than vice versa, leaving more room for discrepancies in the former (i.e. for SBE).

Figure 3 shows the profiles of the East velocity component, each normalized with 


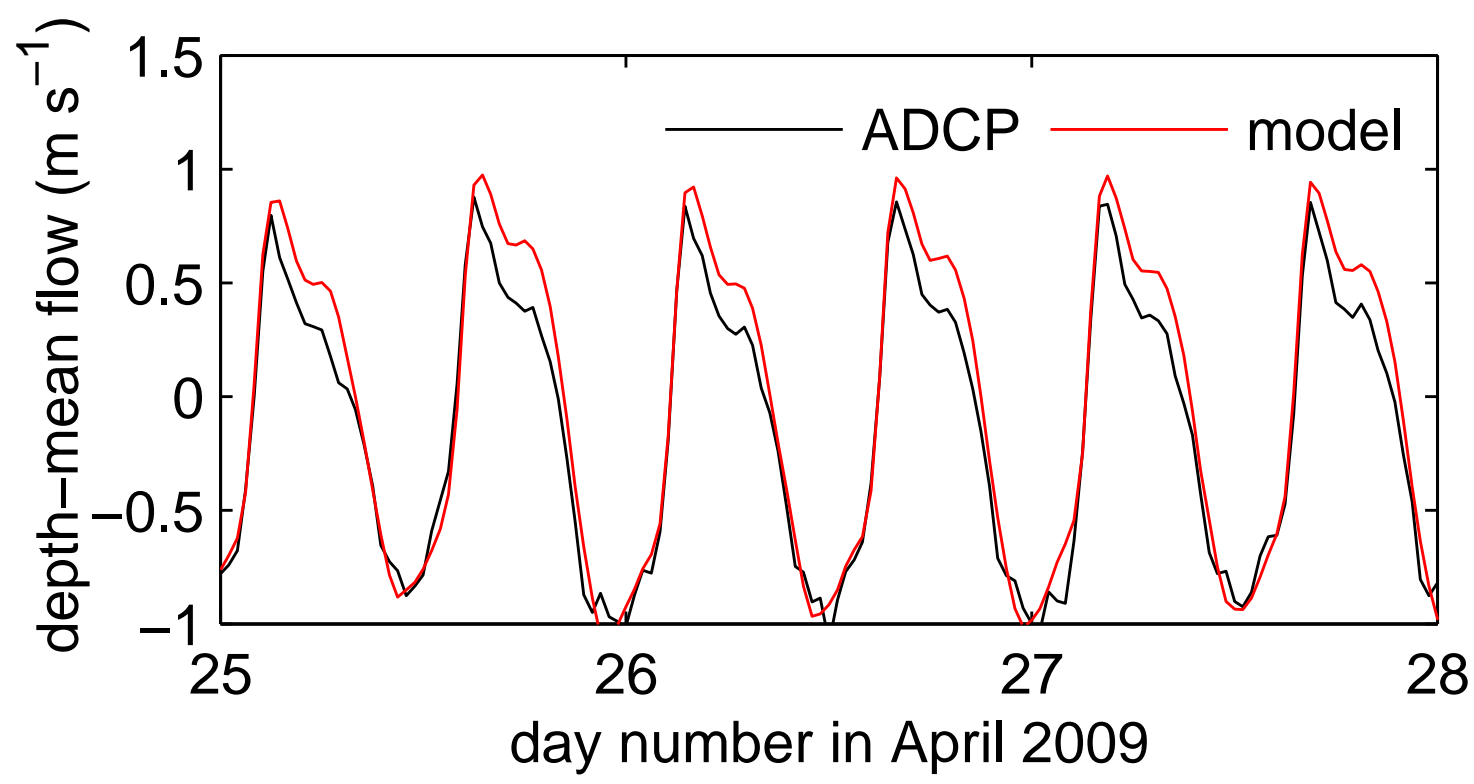

Figure 2: East component of the depth-mean current vector from model and observations. Positive values indicate flood. The time difference in zero-crossing of observed and modeled series is generally greater for Slack Before Ebb (SBE) than for Slack Before Flood (SBF). its corresponding depth-mean velocity, for model and observations during ebb and flood periods. Ebb and flood profiles clearly differ. Flood profiles show a parabolic shape

whereas ebb profiles show a linear shape. These profiles correspond well with recent observations presented by de Vries et al. (2014), who demonstrated that stratification can play a role in determining the structure of the residual current. Here we did not look at stratification in the simulations results or the observations; however, stratification is known to occur throughout the year in the Marsdiep inlet. The shape of the velocity profiles is well represented by the numerical model, except for flood profiles with minor discrepancies in the near-surface that may be associated, for instance, with wind variability and topographic effects in the vicinity of the boundary (e.g. sidewall friction Sassi et al., 2011b).

The qualitative analysis presented above can be further substantiated by performing an Harmonic Analysis (HA) to the modeled and the observed time-series of current profiles (Figure 4). In general, the contribution of the five most important tidal components to the observed and modeled currents agrees relatively well, given the uncertainty associated 

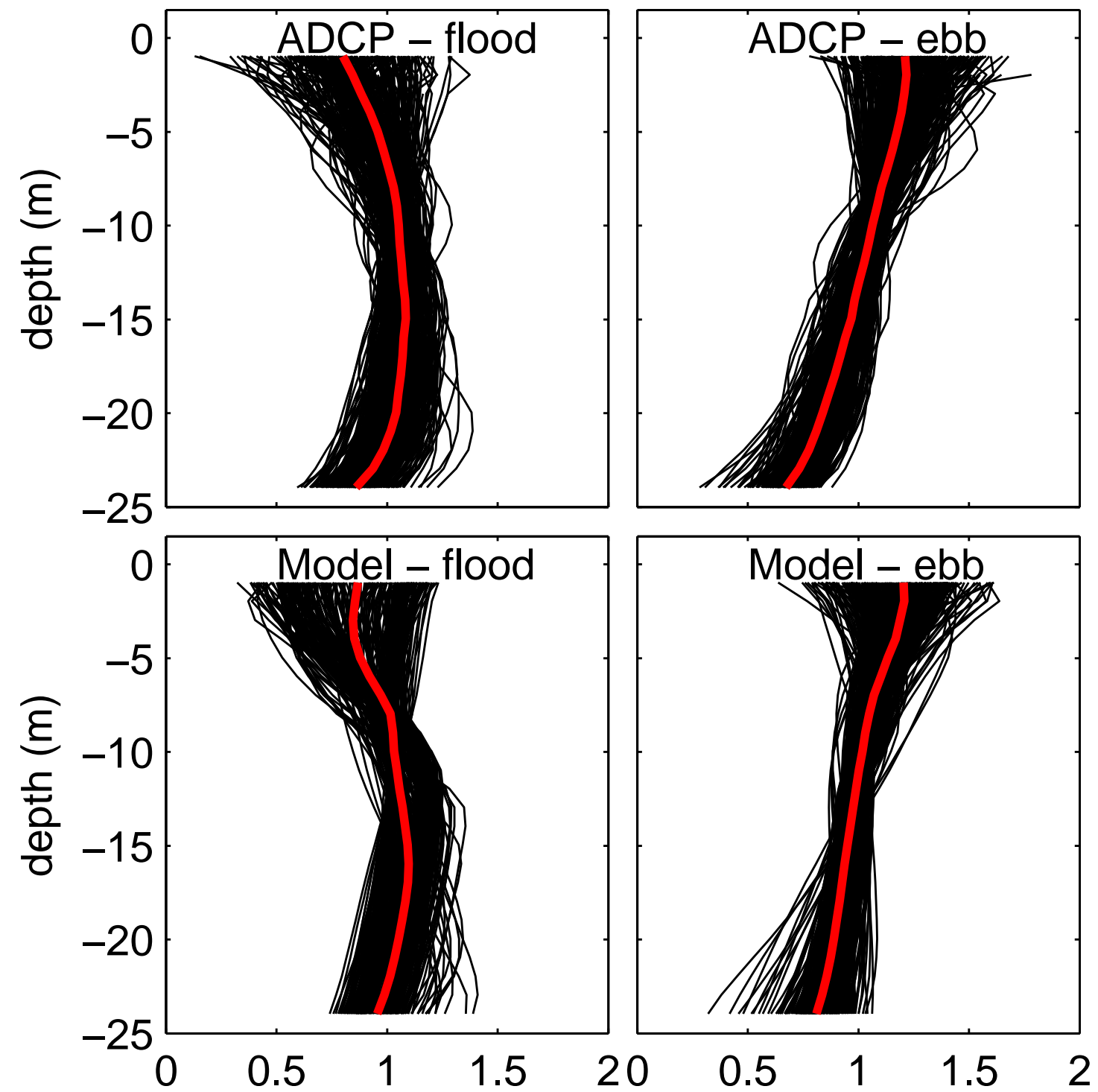

Figure 3: Black lines show the profiles of the East velocity component normalized with the corresponding depth-mean velocity, for model and observations during ebb and flood phases. Profiles shown correspond with those for which the magnitude of the depth-mean velocity is greater than $0.1 \mathrm{~m} \mathrm{~s}^{-1}$. The red lines show the median. 
with the estimates. The model tends to overestimate the semi-diurnal and diurnal components and underestimate the quarter-diurnal component. The difference in phase between model and observations is typically within 5 degrees, except for the quarter-diurnal and diurnal tides.

The model results are quite close to the observations, but the model performance could perhaps be further improved by adopting a different roughness length during ebb and flood periods to reflect the preferential direction of sand-dunes in the Marsdiep inlet (Buijsman and Ridderinkhof, 2008a). Additional sources of discrepancy may be inaccuracies in the representation of the model domain, including the bathymetry of the DWS and the cross-sectional area of the inlet, and local subgrid topographic effects in measured velocity profiles since the lander was located on an area with steep slopes.

\section{b. Velocity Profiles Across the Inlet}

Velocity profiles obtained with the two ADCPs on board the ferry were transformed to sigma-coordinates using the median of the depth measured by the four beams of the ADCP (e.g. Vermeulen et al., 2014), and then sampled onto the model grid using nearest neighbor search with euclidean distance. We then aggregate all velocity measurements falling on a certain grid cell to obtain a fairer comparison with the model output. We further average velocity measurements to $30 \mathrm{~min}$ to match the temporal resolution of the aggregated observations with that of the model output. For each grid point we perform a linear regression with observed velocity as dependent variable and modeled velocity as explanatory variable, and obtain the slope, the offset and the RMSE of the residuals. Since the ferry track spans a great number of grid points (see Figure 5), we split the grid into consecutive transects across the inlet approximately in direction from South to North. This procedure is performed with both East and North components of the velocity vector measured by the two ADCPs, and discriminating between ebb and flood periods. In what follows we show the comparison for the East component measured by the ADCP located on the mainland side and for the flood phase only. 

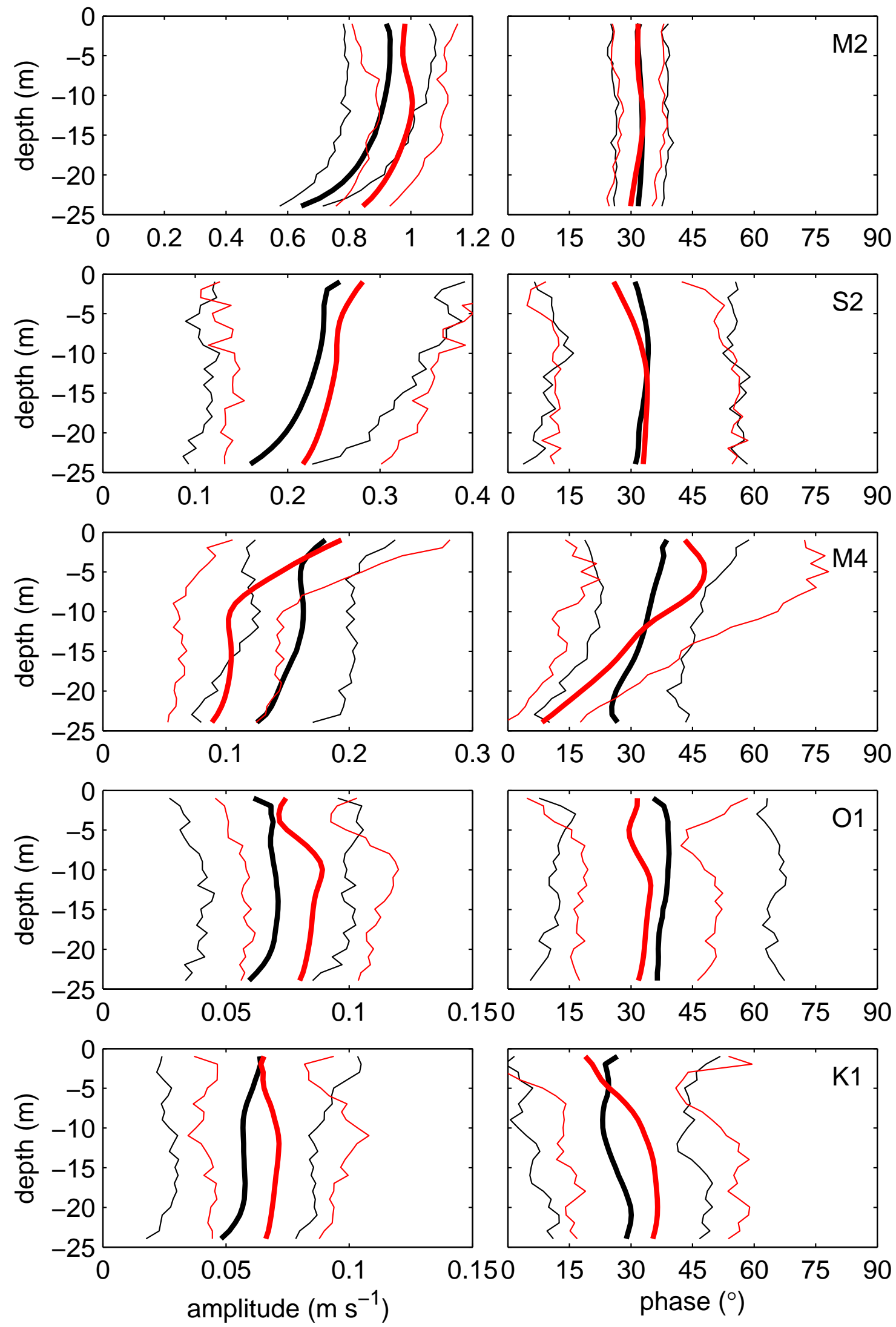

Figure 4: Harmonic analysis (using t_tide) performed on current-vector velocity profiles from observations (black) and simulations (red). The main five tidal constituents are shown, as described (left panels: major senhfaxis; right panels: orientation). Thin lines indicate the error bands. 


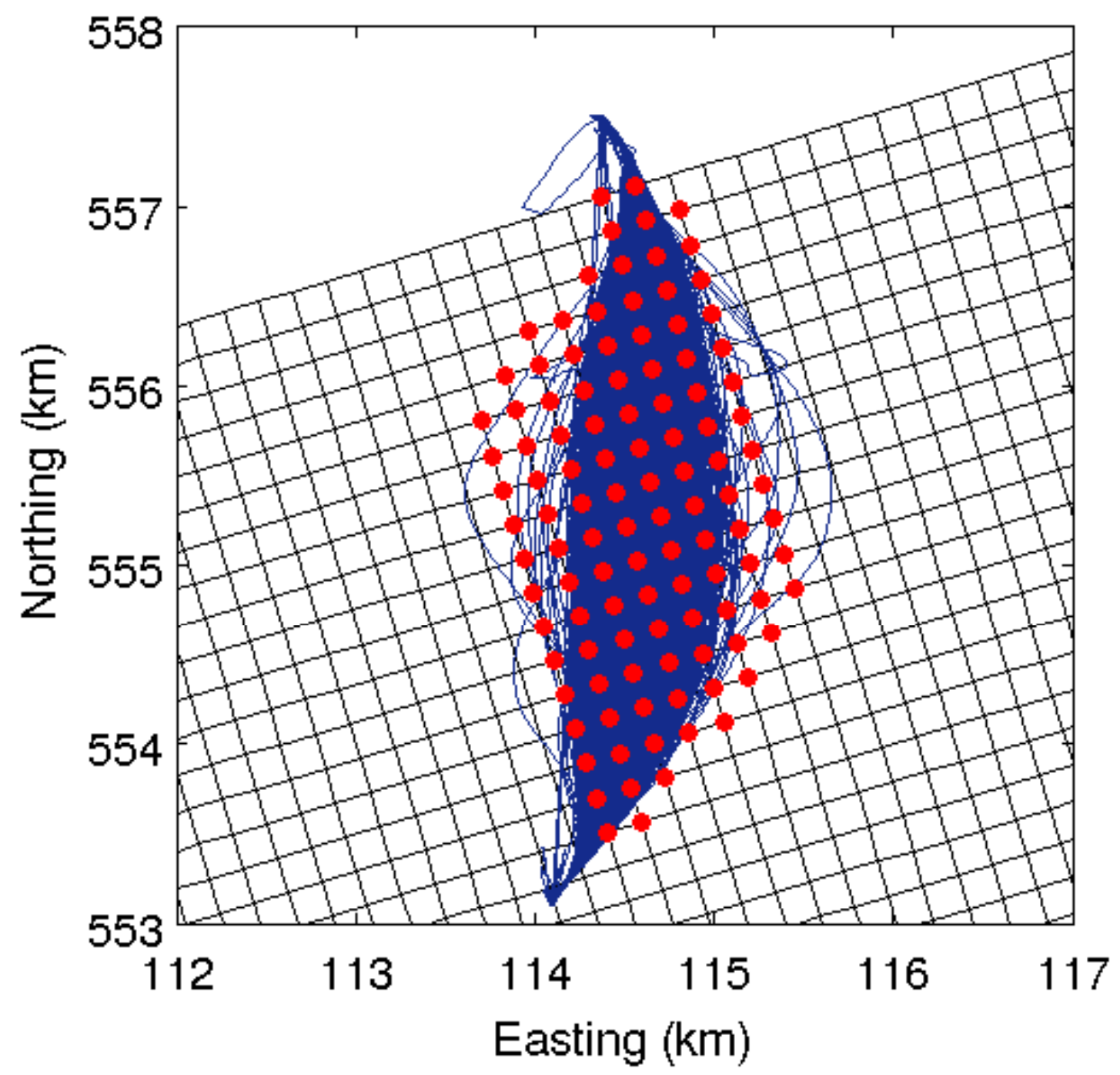

Figure 5: Track of the ferry overlaying the model grid. The red dots indicate the grid points employed for comparison and can be grouped into consecutive transects approximately spanning the inlet from West to East. 
The model slightly overestimates the measured velocities in most parts of the domain of comparison because the slope is typically larger than unity; the offset remains very close to zero in all cases (see Figures 6). Near the bottom and close to the coastlines the model underestimates the observations. Although the latter result seems to be in contradiction with the results presented in Section a., it should also be noted that the location of the lander is well outside the domain of comparison and lies further to the Northeast. As the direction of the main channel is from Southwest to Northeast, we expect the comparison with the lander to be better represented by the comparison in the middle section of the transects shown here. Overall, the agreement between modeled and observed velocities yields a typical error in the range $0.05-0.15 \mathrm{~m} \mathrm{~s}^{-1}$. Comparisons for ebb phases and with the ADCP located at the island side yield similar results (not shown).

\section{c. Transport Through the Inlet}

i. Gross Transport Following the methods described in Section i., we calculate the gross transport through the cross-section with the velocity profiles obtained by each ADCP independently. In a similar fashion, we also compute the transport with modeled profiles but limiting the profiles to the same region as the observations, i.e. below $6.5 \mathrm{~m}$ depth and above the bed starting $6 \%$ of the total water depth. The model output (which has 30-min resolution) is linearly interpolated in time to get a precise correspondence with the ferry crossings, allowing us to compare them one to one.

Air bubbles produced by the wake of the ferry propulsion introduce noise on measured velocity profiles, therefore, we choose to not use data obtained with the ADCP behind the ferry propulsion. Accordingly, we split the observations in three ways: 1) the transport obtained with the ADCP on the island side ignoring the southward crossings, 2) the transport obtained with the ADCP on the mainland side ignoring the northward crossings, and 3) the transport obtained from combining these two. Figure 7 shows a comparison between the modeled and observed transport for a combination of the two ADCPs. The model slightly overestimates the transport, which is consistent with the results in Section a. and b.. With 

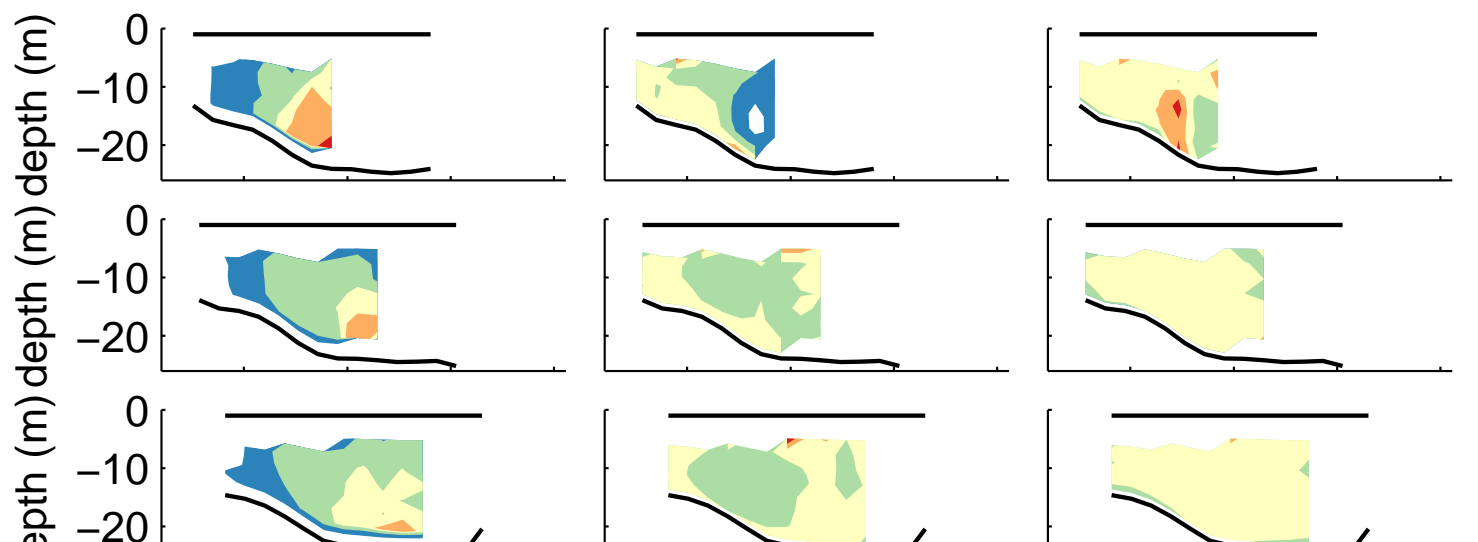

ชิ
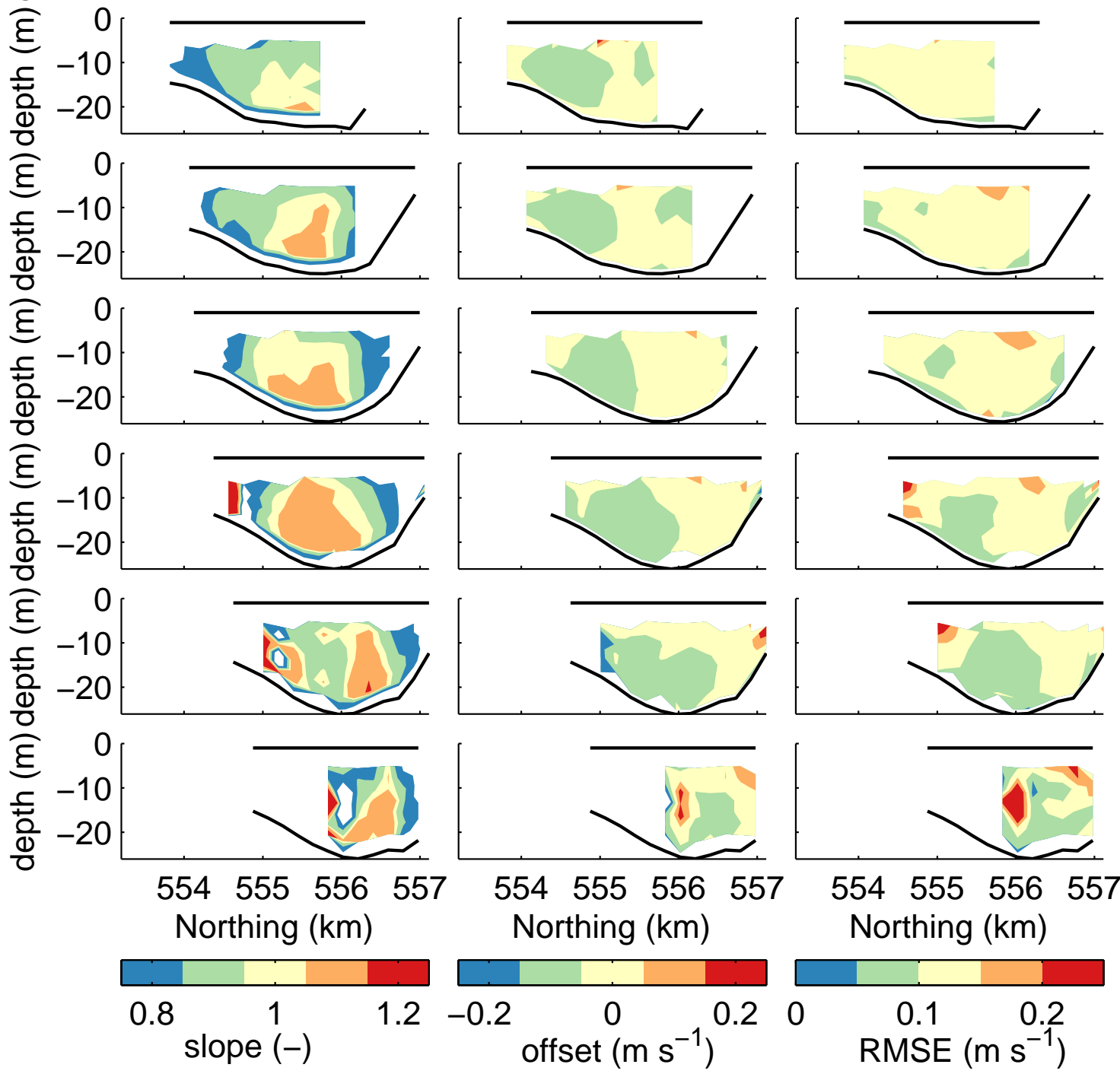

Figure 6: Properties of scatter plots between observed (as explanatory variable) and modeled velocities. For each grid point, a linear regression between time-series of the East component of observed and modeled velocities for flood periods yields the slope, the offset and the RMSE of the residuals. Model grid points were grouped into transects across the Marsdiep (left and right sides of the transect approximately correspond with South and North coastlines of the inlet). Panels from top to bottom represent transects approximately distributed from West to East (see Fig. 5). Also shown the location of the water surface and the bottom. 
any of the three data sources employed in the comparison, the mean bias and the RMSE are on average about $1000 \mathrm{~m}^{3} \mathrm{~s}^{-1}$ and $3500 \mathrm{~m}^{3} \mathrm{~s}^{-1}$, respectively. This is a significant improvement compared with an RMSE of $8000 \mathrm{~m}^{3} \mathrm{~s}^{-1}$ reported by Duran-Matute et al. (2014), and we accredit the latter to the fact that they were comparing the total transport (including extrapolation towards unmeasured areas near surface and bottom), instead of limiting the comparison to the areas that were actually covered by the measurements.

ii. Residual Transport Residuals are calculated over integration (tidal) periods that are defined as follows. We select moments, during rising tides, at which the volume in the DWS matches the long-term mean value; the interval between such consecutive moments is then considered to be the tidal period (see Duran-Matute et al., 2014; Duran-Matute and Gerkema, in prep). This approach yields 690 integration periods for the year 2009; the mean tidal period is 12.42 hours long, but individual periods can vary well within the range 8 to 16 hours, depending on wind conditions (Duran-Matute and Gerkema, in prep). Since the ferry crosses the inlet during daytime, the number of periods to be employed in the comparison is reduced to about half, but this number is further reduced because there are gaps in ADCP data due to ferry maintenance (see Fig. 7) and because the data may not fully cover one tidal period, as shown in the example in Figure 8 . We select only those tidal periods that are fully covered by the data (using the two ADCPs combined) and then linearly interpolate to a common base both model output and observations. A total of 35 tidal periods are employed that allow us to compare one by one the residuals from the model and the observations.

The residual transport is highly variable (Figure 9), not only in magnitude but even in sign; this is in large part due to wind intensity and direction (Duran-Matute et al., 2014; under review). Note that observed residuals typically fall during periods of no strong wind events (i.e. bias towards calm conditions). The range of variation of the residual transport decreases by about an order of magnitude with respect to the gross volumetric transport. Overall, residuals obtained with the ADCP are somewhat smaller 

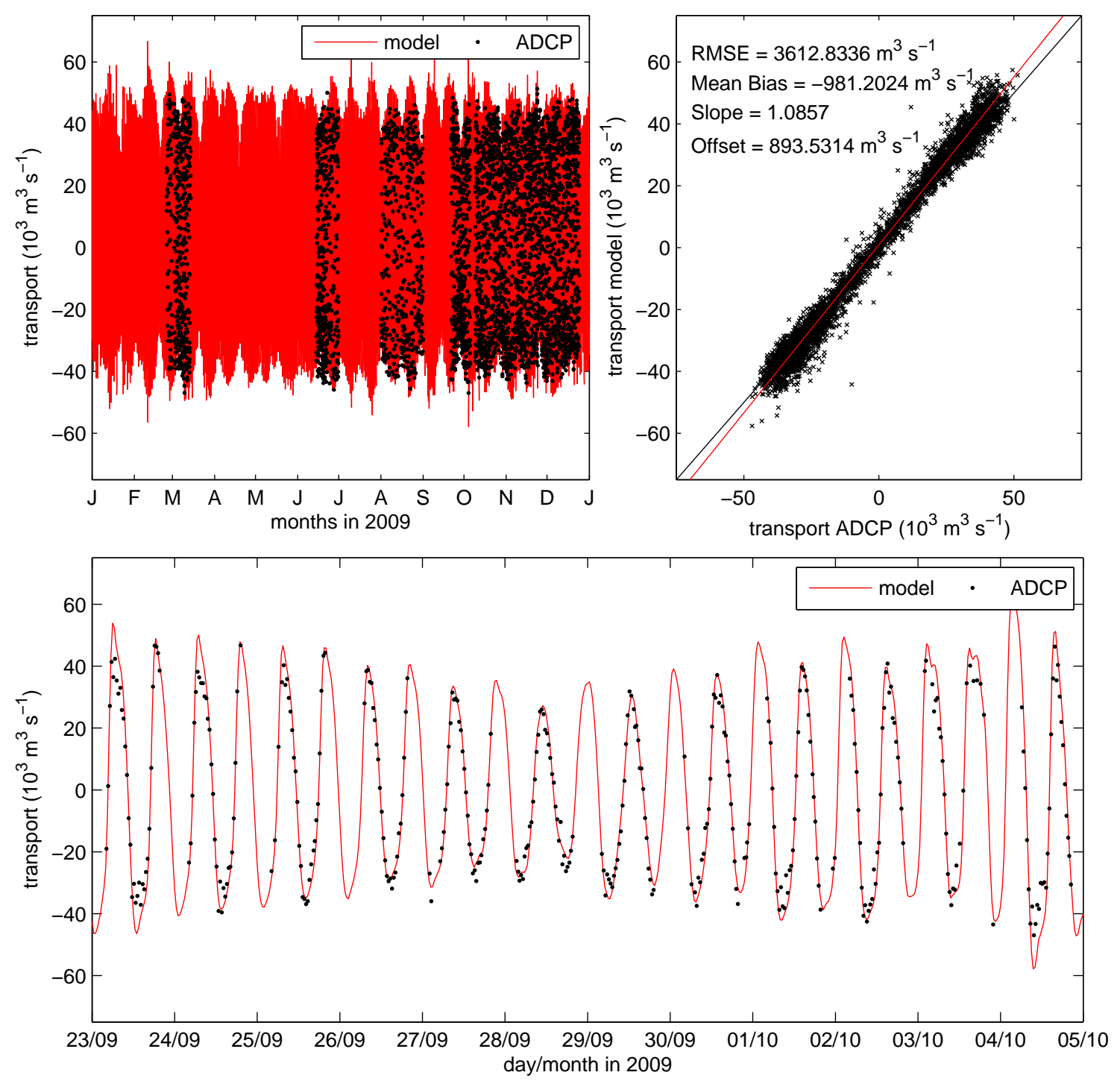

Figure 7: Comparison between the modeled and the observed transport obtained by combining data from the two ADCPs. Modeled transport has been exclusively obtained for areas overlapping with the measured profiles. The panel to the right shows a scatter plot between observations and simulations at times corresponding with the observations. The black line is the one to one line. The red line is the best fit line with slope and offset as described. The panel below shows a sub sample of the time series for a period of about 12 days. 


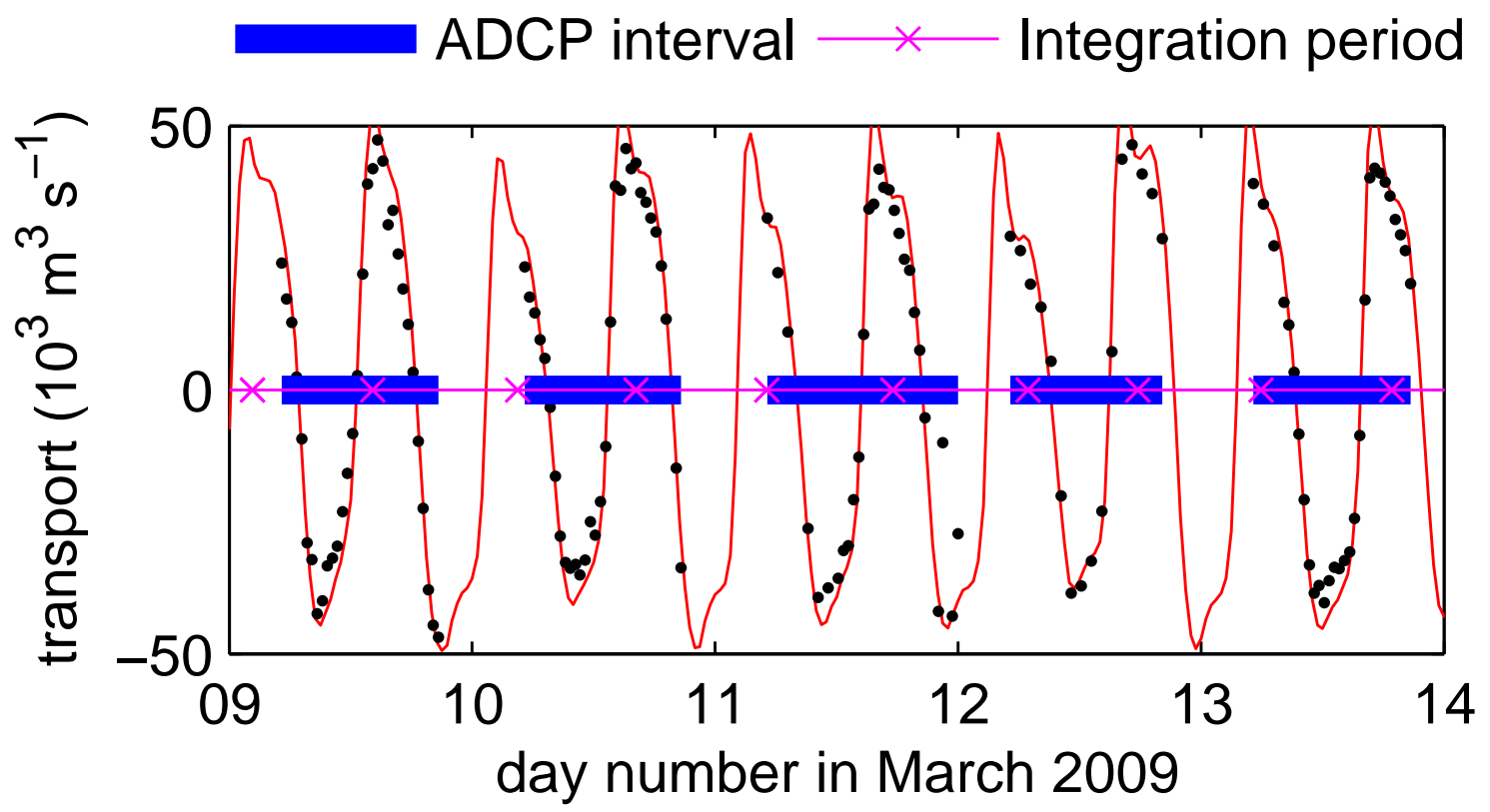

Figure 8: Residuals are computed over predefined integration periods (continuous magenta line with crosses indicating start and end of the interval). The tidal period was defined as the time difference between two consecutive up-crossings of the volume of water of the entire DWS through the median volume (see Duran-Matute et al., 2014). To compare the residuals obtained with the model and the observations, we choose those intervals that are fully covered by ADCP data. In this example we select the two last intervals. 

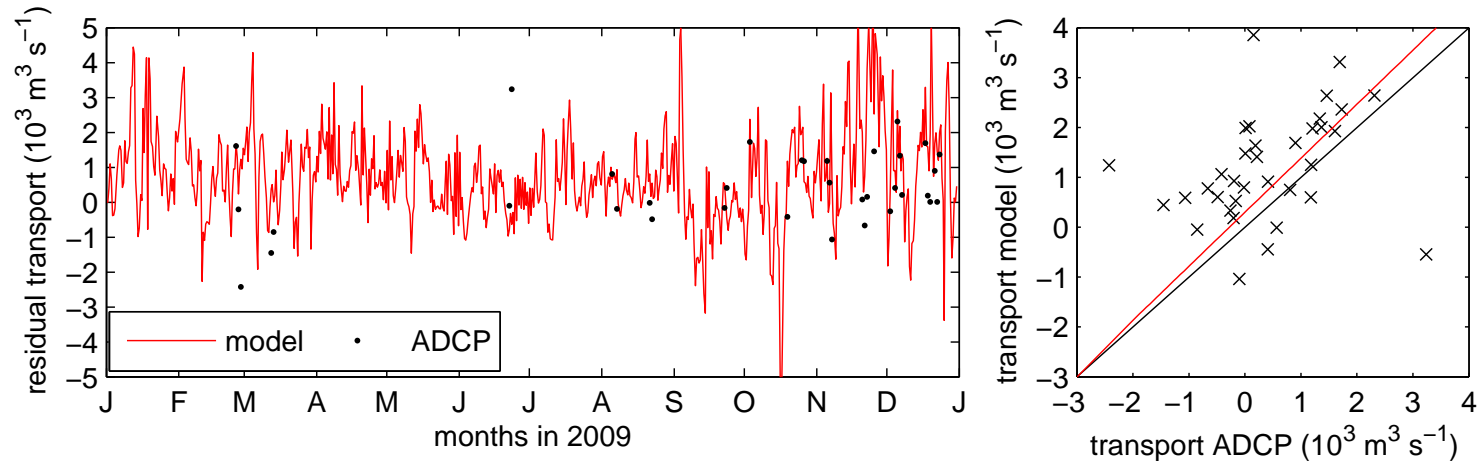

Figure 9: Left: time series of residual transport for the year 2009 from model (continuous red line), and observations (black dots) for the tidal periods that are fully covered by ADCP data. The mean bias is $800 \mathrm{~m}^{3} \mathrm{~s}^{-1}$ and the RMSE is $1200 \mathrm{~m}^{3} \mathrm{~s}^{-1}$. Right: scatter plot with observations as explanatory variably. The black line is the one to one line, and the red line indicates the best fit line with a slope of 1.08 and an offset of $300 \mathrm{~m}^{3} \mathrm{~s}^{-1}$.

compared with the model. This is to be expected as the model typically overestimates the observations. The mean bias is $800 \mathrm{~m}^{3} \mathrm{~s}^{-1}$ and the RMSE is $1200 \mathrm{~m}^{3} \mathrm{~s}^{-1}$. A scatter plot with observations as explanatory variably yields a slope of 1.08 and an offset of $300 \mathrm{~m}^{3}$ $\mathrm{s}^{-1}$

\section{Uncertainty in the Residual Transport}

The modeled and observed transports over the region of the flow that is covered by the ADCP were shown to be in relatively good agreement for gross quantities, and not as good for residual quantities. Although the model overestimates the observations, the behavior is consistent throughout the observations and discrepancies should eventually be minimized after further model calibration. We now investigate the influence of temporal and spatial lacunae in the ADCP data. In particular, we examine how this affects the estimates of the residual flow. We carry out this analysis by taking the model results as a starting point, which have no such gaps; we then artificially erase part of the model data (temporally or spatially) to mimic the gaps of the ADCP coverage. The comparison with the original, full model data then allows us to assess the effects of the gaps and of ways to fill them up. 
418

419

420

421

422

\section{a. Spatial Gaps}

Here we focus on the spatial gaps near the surface and the bottom. Velocity profiles can thus be divided into three regions: a mid layer where the flow is actually measured, and a top and a bottom layer where the flow is not measured. We implement two extrapolation approaches for the unmeasured areas: the 'constant extrapolation method' assumes the uppermost (lowermost) velocity bin is normative of the top (bottom) layer, and the 'linear extrapolation method' assumes the transport in the top layer is determined by the gradient of the three uppermost velocity bins, whereas the transport in the bottom layer is determined by linear interpolation between the lowermost bin and zero at the bottom. The sum of the transports over the three layers gives the transport per unit width, and the sum of the latter over the cross-section yields the total volumetric transport. From the latter we compute the residual transport.

We compute the residual transport from the model data for several possible combinations of approach: using profiles in all three layers, using profiles in the middle layer with no extrapolation, using profiles in the middle layer and extrapolation towards the bottom and the surface using the constant method, and the latter but using the linear method. For the last two approaches we further separate the contributions of bottom and surface extrapolation to the residuals. Table 1 shows a summary of the mean, the median and the standard deviation of the obtained residuals. The median of the true residual for the year 2009 is $-486 \mathrm{~m}^{3} \mathrm{~s}^{-1}$ (out of the DWS), whereas the median of the residual flow computed with the measured region only yields practically the opposite result. Adding the transport near the bottom is not enough to resolve this discrepancy, and extrapolation towards the 40 surface accounts for as much as the true transport. Extrapolation towards the surface us44 ing the constant method marginally improves the comparison and the linear method clearly produces a much better comparison. 


\begin{tabular}{c|cccccccc} 
& Total & Mid & $\begin{array}{c}\text { Mid+Bot } \\
\text { const }\end{array}$ & $\begin{array}{c}\text { Mid+Top } \\
\text { const }\end{array}$ & $\begin{array}{c}\text { Total } \\
\text { const }\end{array}$ & $\begin{array}{c}\text { Mid+Bot } \\
\text { lin }\end{array}$ & $\begin{array}{c}\text { Mid+Top } \\
\text { lin }\end{array}$ & $\begin{array}{c}\text { Total } \\
\text { lin }\end{array}$ \\
\hline Median & -486 & 612 & 627 & 19 & 67 & 615 & -377 & -382 \\
Mean & -8 & 710 & 742 & 252 & 284 & 718 & -17 & -9 \\
SD & 2373 & 1336 & 1452 & 2143 & 2244 & 1365 & 2302 & 2323 \\
RMSE & - & 1521 & 1514 & 649 & 700 & 1518 & 327 & 324 \\
MB & - & 718 & 750 & 260 & 292 & 726 & -9 & -1 \\
Offset & - & 714 & 746 & 259 & 291 & 722 & -10 & -2 \\
Slope & - & 0.5 & 0.53 & 0.88 & 0.91 & 0.51 & 0.96 & 0.97
\end{tabular}

Table 1: Median, mean and Standard Deviation (SD) of the residual transport for the year 2009 , and summary of statistics of the comparison between the residual transport using all measurements (first column) and corresponding estimates based on several approaches with extrapolation towards unmeasured areas (the rest of the columns). The constant extrapolation method (const) assumes that the uppermost (lowermost) velocity bin is normative of the top (bottom) layer. The linear extrapolation method (lin) assumes that the transport in the top layer is determined by the gradient of the three uppermost bins whereas the transport in the bottom layer is determined by linear interpolation between the lowermost bin and zero at the bottom. 'Bot' stands for bottom layer, 'Top' for surface layer, and 'Mid' for middle (measured) layer. All quantities are in $\mathrm{m}^{3} \mathrm{~s}^{-1}$ except for the slope that has no units.

\section{b. Temporal Gaps}

Observations are limited to the time-schedule of the ferry itself, which is mostly from $6 \mathrm{AM}$ to $10 \mathrm{PM}$ (although complete weeks or months lack occasionally due to maintenance). To fill in these temporal gaps we use Harmonic Analysis (HA). First, we assess the effect of the temporal gaps on the results of the HA. We use and compare: 1) the full time series of the modeled transport for the year 2009, 2) the same time series but now restricted to the time schedule of the crossings of the ferry (i.e. from 6 AM to 10 PM), and 3) further restricting the time series to the times and dates that the ferry actually crossed the inlet during the year 2009. Table 2 shows the amplitudes and phases for the main semi-diurnal (M2, S2 and N2), diurnal (O1, P1 and K1), overtides (M4, MS4 and M6), and low-frequency constituents (SSA, MSM and MF). Restricting the series to the ferry times already results in discrepancies of about 1-10\% for quater-diurnal, 5-20\% in diurnal tides, and more than $10 \%$ (and up to above $100 \%$ ) for low-frequency tides; semi-diurnal tides show negligible discrepancies. Restricting the series to the days and times where we 


\begin{tabular}{c|cccccc} 
& \multicolumn{3}{|c}{ Amplitude $\left(\mathrm{m}^{3} \mathrm{~s}^{-1}\right)$} & \multicolumn{3}{c}{ Phase $\left(^{\circ}\right)$} \\
& Full & 6AM-10PM & ADCP Scope & Full & 6AM-10PM & ADCP Scope \\
\hline M2 & 63620 & 63685 & 63390 & 124 & 123 & 123 \\
S2 & 17223 & 17276 & 17129 & 192 & 193 & 193 \\
N2 & 8759 & 8758 & 9151 & 104 & 105 & 105 \\
M4 & 5754 & 5704 & 5353 & 169 & 169 & 159 \\
MS4 & 2707 & 2763 & 3206 & 225 & 222 & 219 \\
M6 & 6372 & 5987 & 5439 & 247 & 241 & 241 \\
O1 & 4249 & 4611 & 4577 & 122 & 124 & 138 \\
P1 & 1649 & 2050 & 1814 & 285 & 282 & 279 \\
K1 & 3748 & 3898 & 3660 & 286 & 282 & 286 \\
SSA & 231 & 451 & 984 & 137 & 130 & 135 \\
MSM & 344 & 564 & 620 & 1 & 6 & 324 \\
MF & 118 & 98 & 674 & 224 & 145 & 225
\end{tabular}

Table 2: Harmonic analysis (using t_tide) on the time series of the modeled transport for the year 2009 (Full), on the same series but restricting the times to daily ferry crossings (6AM-10PM), and further restricting the series to the actual dates and times that the ferry crossed the inlet during the year 2009 (ADCP scope). We obtain amplitudes and phases of several tidal constituents (59 in total) and show here a subset of the most important ones.

457 actually have observations generally amplifies these errors further, except for the diurnal 458 components.

459 To assess the effect of the temporal gaps on the estimation of the residual transport,

time series of the gross transport were reconstructed with the results of the HA. Residuals were then obtained by subtracting the reconstructed series from the original full series. We did this using HA on the full series, on the series corresponding with the daily crossings of the ferry, and on the series with 'maintenance' gaps as in the observations. We also obtained the residuals of the series with gaps, for those integration periods that are fully covered with data (as was previously done with the observations). Table 3 shows a summary of the statistics of the distributions of the residuals obtained with these different approaches. Restricting the series to daily crossings lowers the mean and the median. However, having fewer estimates of the residual, as in the observations during 2009, completely reverses the results. Note that a high correlation coefficient does not guarantee the mean and the median to be representative of the true value. The mean and the median 


\begin{tabular}{c|ccccc} 
& Median & Mean & SD & Skewness & $r$ \\
\hline Full & -486 & -8 & 2373 & 1.2 & - \\
HA Full & -150 & 343 & 3885 & 1.3 & 0.72 \\
6AM - 10PM & -605 & -117 & 2231 & 1 & 0.99 \\
HA 6AM - 10PM & -164 & 416 & 3916 & 1.3 & 0.69 \\
ADCP scope & 588 & 999 & 2333 & 0.7 & 0.99 \\
HA ADCP scope & 274 & 753 & 4210 & 1 & 0.61
\end{tabular}

Table 3: Summary of statistics of the residuals for the year 2009 based on the full series (Full), the series restricted to the times of the ferry crossing (6AM-10PM), the series with gaps as in the observations (ADCP scope), and the residuals obtained by subtracting from the full series the reconstructed series obtained with harmonic analysis. Also shown the Pearson's $r$ between estimates with the full series (first row, assumed here to be the true residual transport) and estimates with all other approaches (the rest of the rows). All quantities in $\mathrm{m}^{3} \mathrm{~s}^{-1}$, except for the skewness and the coefficient of correlation that have no units.

obtained with the HA also show a bias towards positive values, and an almost two-fold increase in the standard deviation of the distribution.

In none of the cases does the residual (mean or median) based on the HA come even close to the value obtained directly from the time series itself. The latter, of course, involves no assumptions and can be considered reliable. The HA, on the other hand, presumes that each constituent has fixed constants of amplitude and phase, which is illusory in an environment where wind-induced set-up can affect the propagation of these very constituents. The problem is aggravated by the fact that periods of strong wind are precisely the times that highly affect the residual flows and their long-term mean.

\section{Discussion}

Ship-borne ADCP measurements offer valuable information, e.g. in our case on the transports through a tidal inlet, but are subject to a number of important uncertainties (Gonzalez-Castro and Muste, 2007), including unmeasured areas, spatial and temporal resolution, Doppler noise, instrumental errors, and operational errors. Each of these errors may introduce large uncertainties when calculating the residual transport. Here we have focused on the uncertainty due to unmeasured areas and gaps in temporal sampling, 
and have found that uncertainty in unmeasured areas (near bottom and surface) can be overcome by linear extrapolation but uncertainty due to temporal sampling is more critical; this is mainly related to the complicated nature of the residuals. Another source of uncertainty that requires further attention in future investigations includes the effects of turbulence (e.g. Tarrab et al., 2012) and noise due to the ferry propulsion on measured velocity profiles and consequently on the volumetric transport. For instance, including nortward and southward crossings in any of the ADCP estimates of the transport yields a worst comparison with the numerical model, with an increase of about $50 \%$ in both the mean bias and the RMSE.

The extrapolation methods employed to fill in the unmeasured areas are considered standard techniques in river discharge monitoring (e.g. Gonzalez-Castro and Muste, 2007), with the power distribution fit complementing the latter set of techniques. Methodologies based on profile fitting (e.g. Sassi et al., 2011b; Pacheco et al., 2012) make use of the best-fit to the observed velocities to extrapolate towards the surface and the bottom, with parameters typically being selected such that the transport through the measured region obtained with the fitted function equals the measured transport. Here we have deliberatively left these methodologies out of the analysis to avoid further complications of the analysis. Although profile fitting techniques would certainly constitute an improvement to our approach, parameterizing near-surface wind effects on velocity profiles is still challenging.

Applying harmonic analysis to time series of transport to fill in the temporal gaps yielded significant errors in the estimated residuals, even when considering the full modeled series with no gaps. This approach for gap-filling in the temporal domain is clearly questionable because harmonic analysis cannot cope with non-linear effects such as those introduced by the varying wind stress forcing. The latter not only varies from one tidal cycle to the other, but also can significantly alter the dominant tidal period. In this respect, approaches based on continuous wavelet transform (Jay and Flinchem, 1997) or 
514 non-stationary tidal harmonic analysis (Matte et al., 2014) may yield more satisfactory 515 results.

516 In this study we have analysed the residual transports of water through the inlet, but the 517 same problems will be encountered when calculating transport of suspended particulate 518 matter. Estimates of the latter in the Marsdiep inlet were made on the basis of acoustic 519 backscatter intensity of the ADCP (Nauw et al., 2014). Based on the present study, we

\section{Conclusions}

Residual flows in multiple-inlet systems control the exchange of mass with the adjacent sea and are of paramount importance for the ecology and the morphology of these environments. Residual flows are difficult to assess because they are very small compared with the instantaneous volumetric transport in a tidal cycle. Moreover, they vary in magnitude and sign from one tidal period to the other due to the combined effects of the tides, the wind and the freshwater discharge, and they even vary from year to year due to climatology. Here we quantified the statistical distribution of residual flows in the Marsdiep tidal inlet of the Wadden Sea by comparing the results of observations with those of a high-resolution numerical model, for the year 2009. Long-term and semi-continuous ferry-based ADCP observations were employed to validate the results of the numerical model, and in turn, the model results were employed to investigate the impact of spatial and temporal gaps in the observations. Areas near the bottom and the surface not covered by the ADCP were supplied with two simple extrapolation methods based on constant and linear extrapolation techniques. Our results indicate that the linear extrapolation technique performs better than the constant extrapolation method, which reflects the strong depar- 
540 tures that wind and freshwater discharge induce in the vertical velocity profiles. This is 541 particularly important near the surface. For the temporal domain (i.e. the gaps in time 542 series of total volumetric transport), we tested the ability of harmonic analysis to properly 543 retrieve the residuals. We found that harmonic analysis yields large departures from the ex544 pected value and, particularly, that harmonic analysis tends to inflate the distribution, with 545 a two-fold increase in the standard deviation. The limited availability of measurements 546 from disruptions due to ferry maintenance and/or other reasons also plays an important 547 role because the statistical distribution of the residuals is poorly sampled.

548 Acknowledgments. This work was supported through the project "PACE The future of 549 the Wadden Sea sediment fluxes: still keeping pace with sea level rise?" by Netherlands 550 organization for scientific research (NWO, ZKO-project 839.11.003). The authors would 551 like to thank Gerben de Boer for fruitful discussions on the handling of the TESO ferry 552 data. The comments by the editor and two anonymous reviewers contributed to improve 553 an earlier version of this manuscript. 


\section{REFERENCES}

M. C. Buijsman and H. Ridderinkhof. Long-term ferry-ADCP observations of tidal currents in the Marsdiep inlet. J. Sea Res., 57(4):237-256, 2007a. doi: 10.1016/j.seares.2006.11.004.

M. C. Buijsman and H. Ridderinkhof. Water transport at subtidal frequencies in the Marsdiep inlet. J. Sea Res., 58(4):255-268, 2007b. doi: 10.1016/j.seares.2007.04.002.

M. C. Buijsman and H. Ridderinkhof. Long-term evolution of sand waves in the Marsdiep inlet. I: High-resolution observations. Cont. Shelf Res., 28(9):1190-1201, 2008a. doi: 10.1016/j.csr.2007.10.011.

M. C. Buijsman and H. Ridderinkhof. Long-term evolution of sand waves in the Marsdiep inlet. II: Relation to hydrodynamics. Cont. Shelf Res., 28(9):1202-1215, 2008b. doi: 10.1016/j.csr.2008.02.014.

H. Burchard and H. Baumert. On the performace of a mixed-layer model based on the $\kappa-\epsilon$ turbulence closure. J. Geophys. Res., 100(C5):8523-8540, 1995. doi: 10.1029/94JC03229.

S.N. Chen and L.P. Sanford. Axial wind effects on stratification and longitudinal salt transport in an idealized, partially mixed estuary. J. Phys. Oceanogr., 39(8):1905-1920, 2009.

D.L. Codiga and D.A. Aurin. Residual circulation in eastern Long Island Sound: Observed transverse-vertical structure and exchange transport. Cont. Shelf Res., 27:103$116,2007$. 
J.J. de Vries, H. Ridderinkhof, L.R.M. Maas, and H.M. van Aken. Intra- and inter-tidal variability of the vertical current structure in the Marsdiep basin. Cont. Shelf Res., in press:in press, 2014.

M. Duran-Matute and T. Gerkema. Calculating residual flows through a multiple-inlet system: the conundrum of the tidal period. Ocean Dynam., in press:1461-1475, 2015. doi: 10.1007/s10236-015-0875-1.

M. Duran-Matute, T. Gerkema, and M.G. Sassi Anisotropic response to wind forcing of the residual circulation in a multiple-inlet system: the case of the western Dutch Wadden Sea. J. Geophys. Res., submitted:submitted, submitted.

M. Duran-Matute, T. Gerkema, G.J. de Boer, J.J. Nauw, and U. Gräwe. Residual circulation and freshwater transport in the Dutch Wadden Sea: a numerical modelling study. Ocean Sci., 10:611-632, 2014. doi: 10.5194/os-10-611-2014.

E.P.L. Elias, J. Cleveringa, M.C. Buijsman, J.A. Roelvink, and M.J.F. Stive. Field and model data analysis of sand transport patterns in Texel Tidal inlet (the Netherlands). Coast. Eng., 53:505-529, 2006. doi: 10.1016/j.coastaleng.2005.11.006.

A.C.R. Esparza, P. Douillet, and J. Zavala-Hidalgo. Tidal dynamics of the Terminos Lagoon, Mexico: observations and 3D numerical modelling. Ocean Dynam., 64(9):13491371, 2014. doi: 10.1007/s10236-014-0752-3.

J.A. Gonzalez-Castro and M. Muste. Framework for estimating uncertainty of ADCP measurements from a moving boat by standardized uncertainty analysis. J. Hydraul. Eng., 13(12):1390-1410, 2007.

D. A. Jay and E. P. Flinchem. Interaction of fluctuating river flow with a barotropic tide: A demonstration of wavelet tidal analysis methods. J. Geophys. Res., 102:5705-5720, 1997. doi: 10.1029/96JC00496. 
C. Li. Subtidal water flux through a multiple-inlet system: Observations before and during a cold front event and numerical experiments. J. Geophys. Res., 118:1877-1892, 2013. doi: 10.1002/jgrc.20149.

P. Matte, Y. Secretan, and J. Morin. Temporal and spatial variability of tidal-fluvial dynamics in the St. Lawrence fluvial estuary: An application of nonstationary tidal harmonic analysis. J. Geophys. Res., 119(9):5724-5744, 2014. doi: 10.1002/2014JC009791.

M. Muste, K. Yu, and M. Spasojevic. Practical aspects of ADCP data use for quantification of mean river flow characteristics; Part I: moving-vessel measurements. Flow Meas. Instrum., 15:1-16, 2004.

J.J. Nauw, Merckelbach, H. L.M., Ridderinkhof, and H.M. van Aken. Long-term ferry-based observations of the suspended sediment fluxes through the Marsdiep inlet using acoustic Doppler current profilers. J. Sea Res., 87:17-29, 2014. doi: 10.1016/j.seares.2013.11.013.

A. Pacheco, A. Ferreira, J. J. Williams, E. Garel, A. Vila-Concejo, and J. A. Dias. Hydrodynamics and equilibrium of a multiple-inlet system. Mar. Geol., 274(1-4):32-42, 2010. doi: 10.1016/j.margeo.2010.03.003.

A. Pacheco, 1. Faísca, 1. Almeida, O. Ferreira, J.J. Williams, and J. A. Dias. A statistical evaluation of models for extrapolating current velocities from boat-mounted ADCP profiles. Coast. Eng. J., 54(03):1250018, 2012. doi: 10.1142/S0578563412500180.

H. Ridderinkhof. Tidal and residual flows in the Western Dutch Wadden Sea I: Numerical model results. Neth. J. Sea Res., 22(1):1-21, 1988a. doi: 10.1016/0077-7579(88)90049$\mathrm{X}$.

H. Ridderinkhof. Tidal and residual flows in the Western Dutch Wadden Sea II: An analytical model to study the constant flow between connected tidal basins. Neth. J. Sea Res., 22(3):185-198, 1988b. doi: 10.1016/0077-7579(88)90022-1. 
P. Salles, G. Voulgaris, and D. G. Aubrey. Contribution of nonlinear mechanisms in the persistence of multiple tidal inlet systems. Estuar. Coast. Shelf. Sci., 65(3):475-491, 2005. doi: 10.1016/j.ecss.2005.06.018.

M. G. Sassi, A.J.F. Hoitink, B. de Brye, B. Vermeulen, and E. Deleersnijder. Tidal impact on the division of river discharge over distributary channels in the Mahakam Delta. Ocean Dynam., 61:2211-2228, 2011a. doi: 10.1007/s10236-011-0473-9.

M.G. Sassi, A.J.F. Hoitink, B. Vermeulen, and Hidayat. Discharge estimation from HADCP measurements in a tidal river subject to sidewall effects and a mobile bed. Water Resour. Res., 47(W06504), 2011b. doi: 10.1029/2010WR009972.

M.E. Scully, C. Friedrichs, and J. Brubaker. Control of estuarine stratification and mixing by wind-induced straining of the estuarine density field. Estuaries, 28(3)321-326, 2005. doi: 10.1007/BF02693915.

E.V. Stanev, J.O. Wolff, H. Burchard, K. Bolding, and G. Flöser. On the circulation in the East Frisian Wadden Sea: numerical modeling and data analysis. Ocean Dynam., 53(1):27-51, 2003. doi: 10.1007/s10236-002-0022-7.

L. Tarrab, C. M. García, M. I. Cantero, and K. Oberg. Role of turbulence fluctuations on uncertainties of acoustic Doppler current profiler discharge measurements. Water Resour. Res., 48(6), 2012. doi: 10.1029/2011WR011185.

C.L. Trump, and G.O. Marmorino. Calibrating a gyrocompass using ADCP and DGPS data. J. Atmos. Oceanic Technol., 14:211-213, 1997.

A. Valle-Levinson K.C. Wong, and K.T Bosley. Observations of the wind-induced exchange at the entrance to Chesapeake Bay. J. Mar. Res., 59:391-416, 2001.

J. van de Kreeke. Can multiple inlets be stable? Estuar. Coast. Shelf. Sci., 30:261-273, 1990. 
649 B. Vermeulen, M.G. Sassi, and A.J.F. Hoitink. Improved flow velocity estimates from 650 moving-boat ADCP measurements. Water Resour. Res., 50:4186-4196, 2014. doi: $651 \quad 10.1002 / 2013$ WR015152.

652 K.C. Wong, and A. Valle-Levinson. On the relative importance of the remote and local 653 wind effects on the subtidal exchange at the entrance to the Chesapeake Bay. J. Mar. 654 Res., 60:477-498, 2002. 